\title{
Multiple splice variants within the bovine silver homologue (SILV) gene affecting coat color in cattle indicate a function additional to fibril formation in melanophores Christa Kuehn* and Rosemarie Weikard
}

Address: Research Institute for the Biology of Farm Animals (FBN), Res. Unit Molecular Biology, Wilhelm-Stahl-Allee 2, D-18196 Dummerstorf, Germany

Email: Christa Kuehn* - kuehn@fbn-dummerstorf.de; Rosemarie Weikard - weikard@fbn-dummerstorf.de

* Corresponding author

Published: 24 September 2007

BMC Genomics 2007, 8:335 doi:10.1/86/147|-2164-8-335
Received: 24 May 2007

Accepted: 24 September 2007

This article is available from: http://www.biomedcentral.com/I47I-2/64/8/335

(c) 2007 Kuehn and Weikard; licensee BioMed Central Ltd.

This is an Open Access article distributed under the terms of the Creative Commons Attribution License (http://creativecommons.org/licenses/by/2.0), which permits unrestricted use, distribution, and reproduction in any medium, provided the original work is properly cited.

\begin{abstract}
Background: The silver homologue(SILV) gene plays a major role in melanosome development. SILV is a target for studies concerning melanoma diagnostics and therapy in humans as well as on skin and coat color pigmentation in many species ranging from zebra fish to mammals. However, the precise functional cellular mechanisms, in which SILV is involved, are still not completely understood. While there are many studies addressing SILV function upon a eumelaneic pigment background, there is a substantial lack of information regarding the further relevance of SILV, e.g. for phaeomelanosome development.
\end{abstract}

Results: In contrast to previous results in other species reporting SILV expression exclusively in pigmented tissues, our experiments provide evidence that the bovine SILV gene is expressed in a variety of tissues independent of pigmentation. Our data show that the bovine SILV gene generates an unexpectedly large number of different transcripts occurring in skin as well as in non-pigmented tissues, e.g. liver or mammary gland. The alternative splice sites are generated by internal splicing and primarily remove complete exons. Alternative splicing predominantly affects the repeat domain of the protein, which has a functional key role in fibril formation during eumelanosome development.

Conclusion: The expression of the bovine SILV gene independent of pigmentation suggests SILV functions exceeding melanosome development in cattle. This hypothesis is further supported by transcript variants lacking functional key elements of the SILV protein relevant for eumelanosome development. Thus, the bovine SILV gene can serve as a model for the investigation of the putative additional functions of SILV. Furthermore, the splice variants of the bovine SILV gene represent a comprehensive natural model to refine the knowledge about functional domains in the SILV protein. Our study exemplifies that the extent of alternative splicing is presumably much higher than previously estimated and that alternatively spliced transcripts presumably can generate molecules of deviating function compared to their constitutive counterpart. 


\section{Background}

The silver homologue(SILV) gene has been a target for many investigations concerning development of melanosomes, which are the specific pigment carrying compartments within melanophores, e.g. in melanocytes. In humans, SILV plays a major role in studies regarding melanoma diagnosis and therapy, because SILV is a sensitive melanoma marker on transcript and protein level $[1,2]$ and represents a melanoma specific antigen recognized by tumor infiltrating cytotoxic T lymphocytes [3]. The SILV protein also known as PMEL17, GP100 or ME20 [4] is crucial for proper formation and maturation of melanosomes. In stage II melanosomes, processed SILV protein aggregates to form fibrils, to which presumably the eumelanin pigment is attached [5]. Due to its role in melanosome development, SILV has also been subject to several studies investigating the genetic background of coat color.

Coat color phenotype in mammals is dependent on a series of genes determining distribution of melanocytes (e.g. KIT, [6]), synthesis of the two essential pigments, eumelanin (black) and phaeomelanin (red) (e.g. MC1R, [7]), and intra- and intercellular transport mechanisms of proteins relevant for coat color expression (e.g. MATP, [8]). In cattle, variants in the MC1R gene result in exclusively eumelaneic (black) or phaeomelaneic (red) skin [9]. Spotted individuals exhibit delimited, white skin areas lacking melanocytes similar to piebald mice [10]. Similar to other species, dilution loci resulting in a diluted type of the original coat color are known in cattle, e.g. the Dilution locus in the Charolais breed (Dc). The putative role of SILV for various coat color dilution loci was described in a number of species, including mouse, dog, chicken, horse, and cattle [11-16]. There is concurring indication that concerning coat color the effect of a mutation in the SILV gene in mouse, horses and dogs seems to be restricted to the dilution of eumelaneic pigment. This is underlined by experiments in mice indicating that SILV expression seems to be restricted to melanocytes expressing eumelanin [17]. In cattle, however, there is still some controversy regarding the potential role of SILV in phaeomelanosome development, because up to now there is no unequivocal experimental evidence rejecting or propagating SILV mutations as causal background for phaeomelanin dilution $[14,18]$. First reports on splice variants for the human SILV gene [19] and a retroposon insertion in intron 10 of the canine SILV gene that seems to affect the correct splicing of the gene in merle dogs [12] raise the question whether putative splice variants of the SILV gene may be specifically involved in melanosome development. Comprehensive studies in humans revealed that alternative splicing is a frequent mechanism altering spatial expression pattern and function of proteins [20,21].
In the present study, we present a comprehensive description of the complex expression pattern of the bovine SILV gene in pigmented and non-pigmented tissues. Multiple transcript variants affecting functional key domains of the SILV protein indicate that the bovine SILV gene may serve as a model for investigations about alternative splicing to generate molecules of obviously deviating function compared to constitutive transcripts.

\section{Results \\ Identification of the SILV transcription start site}

Analysis of several 5'RACE clones from total RNA of eumelaneic, non-dilute (black) skin indicated a sharp peak of transcription start sites (TSS) at position -28 bp to the A of the translation start ATG of the SILV gene (GenBank: EF065525). No further promoters were detected. The SILV transcription start obtained in this study adds an additional 7 bp to the previously deposited bovine SILV cDNA sequence [14]. The cDNA sequence generated by this experiment based on CAP carrying full length mRNA confirmed previous findings about the structure of the bovine SILV gene comprising 2046 bp organized in 11 exons (Figure 1) and encoding 649 amino acids. Aligning the obtained SILV CDNA sequence with the bovine genomic contig NCBI: NW_001495046 [22]) indicated that the bovine SILV gene spans a total of 8107 bp with introns sizes ranging from 108 to $2220 \mathrm{bp}$. A TTATA motif representing the putative TATA box of the SILV promoter is located $30 \mathrm{bp}$ upstream of the transcription initiation site.

\section{Detection of splice variants}

Multiple RT-PCR fragments were detected when amplifying SILV cDNA from RNA of eumelaneic (black), nondiluted skin with primers in the 5' and 3' UTR of the SILV gene $\left(5 \mathrm{UTR}_{\mathrm{F} 1}-\mathrm{E} 11_{\mathrm{R} 2}\right.$; Table 1,2$)$. This diversity of transcripts was also obtained with a primer combination spanning exon 1 to exon $7\left(\mathrm{E} 1_{\mathrm{F} 3}-\mathrm{E} 7_{\mathrm{R} 1}\right)$ of the bovine SILV gene (Figure 2). While the constitutive transcripts (2039 bp or 1430 bp, respectively, confirmed by sequencing) were dominating, further fragments up to $900 \mathrm{bp}$ smaller than the constitutive transcript were identified with both primer pairs. In contrast, cloned SILV constitutive cDNA yielded only the expected 2039 or 1430 bp PCR fragment, respectively.

A series of PCR amplifications in SILV cDNA samples with primers dissecting the transcribed SILV sequence into smaller segments enabled a better discrimination of the generated fragments. Exons 6, 8 and 9 were identified as putative regions for alternative splicing events, because at least two RT-PCR fragments could be unambiguously discriminated with primer combinations spanning exon 5 7 (E5F1 - E7R1) and exon 7 - 11 (E7F1 - E11R2). In contrast, only single RT-PCR fragments were observed for the 


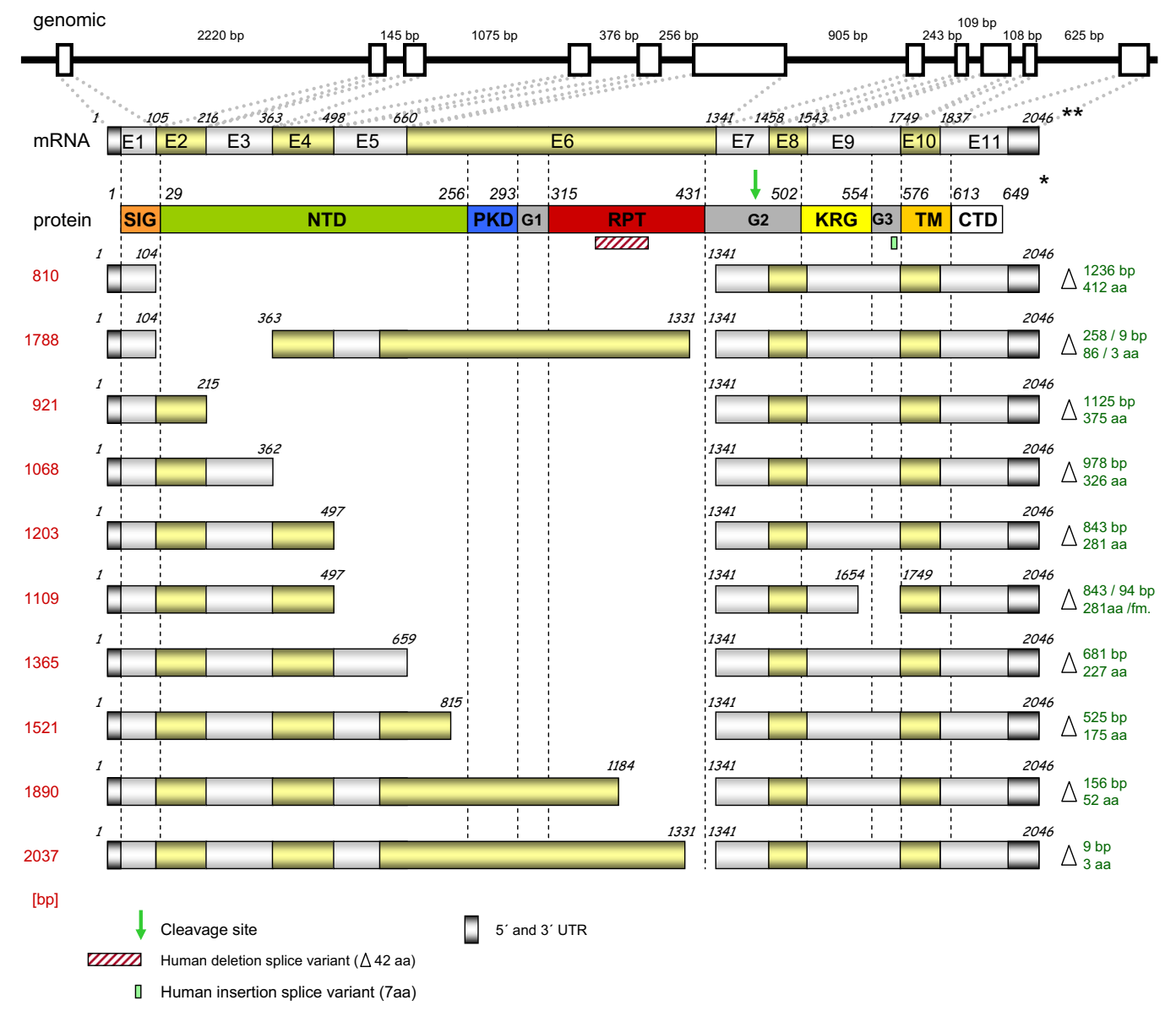

\section{Figure I}

Structure of the bovine SILV mRNA including alternative transcripts. Position of exons (open boxes) and introns (solid line) in the SILV genomic sequence are indicated. Protein domains according to [4,3I] are shown: SIG: signal peptide, NTD: N-terminal domain, PKD: polycystic kidney domain, RPT: repeat domain, KRG: Kringle-like domain, TM: transmembrane domain, CTD: C-terminal domain, GI, G2, G3: undefined domains. E: SILV exon.* Numbers in the SILV protein diagram represent the first amino acid of the respective domain. ** Numbers for the SILV transcripts represent the first nucleotide for the respective exon or the last constitutive nucleotide of an alternative transcript. fm: frame shift mutation. Length [in bp] of the alternative c SILV transcripts is indicated in red (left), the missing part relative to the constitutive SILV transcript (nucleotides and amino acids) is indicated in green (right).

primer combinations covering exon $1-3$, exon $3-5$, exon $5-6$, exon $9-11$ and exon $10-11$. Notably, all identified fragments were present in all differentially pigmented skin samples investigated (Table 2, Figure 3). Our data show that the expression of the bovine SILV gene is not restricted to eumelaneic (black), non-dilute (Dcd/ Dcd) skin, but also occurs in skin expressing exclusively phaeomelanin. Furthermore, also white skin sections of spotted individuals with eumelaneic or phaeomelaneic background showed SILV gene expression as well as the crème white skin of a eumelaneic homozygous dilute DcD/DcD individual.
The SILV transcripts additional to the constitutive fragment that had been identified by RT-PCR were isolated from the agarose gel and sequenced to reveal the specific DNA sequence of the different fragments. Alignment of the obtained sequences to the reference constitutive cDNA (GenBank: EF065525) showed that the additional SILV transcripts lacked different parts of the SILV mRNA (Figure 1). With primers spanning exon 5 to exon $7\left(\mathrm{E} 5_{\mathrm{F} 1}-\right.$ E7 ${ }_{\mathrm{R} 1}$ ), three alternative transcripts (according to GenBank: EF065525) were characterized: $\Delta 660-1340$ lacking 681 bp corresponding to the entire exon $6, \Delta 816-1340$ lacking 525 bp from the 3 ' end of exon 6 and $\Delta 1185-1340$ lacking $156 \mathrm{bp}$ from the 3 ' end of exon 6 . With primers span- 
Table I: Primers for reverse transcription and amplification in the bovine SILV gene

\begin{tabular}{|c|c|c|c|}
\hline Name & Position $^{\mathrm{a}}$ & Exon & Sequence $\left(5^{\prime}-3^{\prime}\right)$ \\
\hline $\mathrm{EI}_{\mathrm{F} 3}$ & 69 & $\mathrm{I}$ & TGATGGGTGTTCTTCTGGCTG \\
\hline $\mathrm{E} 3_{\mathrm{FI}}$ & 280 & 3 & CTCTATTGCCTTGCACTTTCC \\
\hline$E 3_{\mathrm{RI}}$ & 362 & 3 & CATTGATGATGGTGTTGTTGG \\
\hline$E 5_{\mathrm{RI}}$ & 656 & 5 & TAATGGTGAAGGCTGAACTGG \\
\hline $\mathrm{E} 5_{\mathrm{FI}}$ & 575 & 5 & AACATGGAAGTGACTGTCTACC \\
\hline$E 7_{\mathrm{RI}}$ & 1430 & 7 & AGCCATAGCGATACAGAACAC \\
\hline$E 7_{\mathrm{FI}}$ & 1360 & 7 & GGATGACACTGCCACCTTAG \\
\hline$E I I_{R 2}$ & 2046 & 11 & AGGGAAGACCAGAGAAAAGAC \\
\hline $\mathrm{E}_{\mathrm{F} 2}$ & 952 & 6 & CACTACAGATAGGCATGTGAC \\
\hline $\mathrm{E} 6_{\mathrm{R} 2}$ & 1030 & 6 & GCCCATGACTTCTGTAGTAGG \\
\hline $\mathrm{EIO}$ & 1773 & 10 & СTCСTCTGTTCGTGGGCATC \\
\hline $\mathrm{E} 9_{\mathrm{Fl}}$ & 1643 & 9 & GTTTTGCACCAGGTACTGAAG \\
\hline RACE_E7N & $|44|$ & 7 & CAGGGTGAGGGAAAAGGAGCCATAG \\
\hline $5 U T R_{\mathrm{FI}}$ & 8 & $\mathrm{I}$ & GTTGCTGGAAGGAAGAACAGG \\
\hline $\mathrm{SPex} 23_{\mathrm{FI}}$ & 88 & $1 / 4$ & TGTAGGGACCACAGAAGGGAG \\
\hline$E 5_{\mathrm{RI}}$ & 656 & 5 & TAATGGTGAAGGCTGAACTGG \\
\hline $\mathrm{SPex} 56_{\mathrm{FI}}$ & 481 & $4 / 7$ & TGTCTGGAAGACCTGGGGCT \\
\hline$E 9_{R 2}$ & 1587 & 9 & TGACACCCTGGCGATGAGATG \\
\hline $\mathrm{E}_{\mathrm{F} 2}$ & 565 & 5 & GGGCACATATAACATGGAAGTG \\
\hline$S P e x 6_{R I}$ & 1358 & $7 / 5$ & GCAGGGGACTCAGGGAGCCAG \\
\hline $\mathrm{SPe} 6 \mathrm{~A}_{\mathrm{FI}}$ & 798 & $6 / 7$ & CCTACACCTGGGACTTTGGCT \\
\hline $\mathrm{SPe} 6 \mathrm{~B}_{\mathrm{FI}}$ & 1167 & $6 / 7$ & CAACTGCAAAAGCTACAG $\overline{\overline{G C T}}$ \\
\hline $\mathrm{E} 7_{\mathrm{F} 2}$ & 1409 & 7 & TGTGTTCTGTATCGCTATGGCTC \\
\hline $\operatorname{SPex} 9_{R I}$ & 1767 & $9 / 10$ & CTGAGGCCTGCTTCTTGCCETG \\
\hline
\end{tabular}

a Position within the bovine SILV mRNA (according to GenBank: EF065525). Underlined, bold sequence: nucleotides specific for alternative splice site.

ning exon 7 to exon $11\left(\mathrm{E} 7_{\mathrm{R} 1}-\mathrm{E} 11_{\mathrm{R} 2}\right)$, we obtained an alternative transcript $\Delta 1655-1748$ lacking 94 bp from the 3 ' end of exon 9. Furthermore, sequencing of an additional RT-PCR transcript amplified with primers from exon 1 and exon $11\left(5 \mathrm{UTR}_{\mathrm{F} 1}-\mathrm{E} 11_{\mathrm{R} 2}\right)$ detected a SILV cDNA $\Delta 498-1340 / \Delta 1655-1748$ lacking exon 5, exon 6 and 94 bp from the 3 ' end of exon 9 (Figure 1).

Diversity in SILV transcripts was also confirmed in the course of our 5'RACE experiments. Several clones containing inserts smaller than the expected size (1441 bp) were detected. Sequencing of the respective clones revealed $S I L V$ cDNAs starting from the identified transcription start, but devoid of distinct other regions in the remaining SILV mRNA. On the one hand, we received transcripts confirming already detected alternative splice variants e.g., $\Delta 498-1340, \Delta 660-1340, \Delta 816-1340$, and $\Delta 1185-$ 1340. Additionally, we identified two further internal splice sites generating a transcript $\Delta 105-362$ (skipping exons 2 and 3 )/ $\Delta 1332-1340$ (lacking 9 bp at the 3 ' end of exon 6 (Figure 1).

In order to obtain indication whether combinations of alternative splicing events occurred, we sequenced a collection of clones from a plasmid library containing SILV RT-PCR products of variable size generated by cDNA amplification of eumelaneic (black), non-dilute $\left(D c^{d} / D c^{d}\right)$ skin with primers spanning exon 1 to exon $7\left(\mathrm{E} 1_{\mathrm{F} 3}-\mathrm{E} 7_{\mathrm{R} 1}\right)$. Alignment of the generated sequences to the SILV constitutive transcript confirmed previously detected transcripts and yielded an additional new series of transcripts (Figure 1) with deleted exons: $\Delta 363$ - 1340 (lacking exon $4-6$ ), $\Delta 216$ - 1340 (lacking exon 3 - 6) and $\Delta 105$ - 1340 (lacking exon $2-6$ ).

Only some alternative internal splice sites completely conformed to the GT-AG rule for splice donor and splice acceptor sites. Notably, the alternative splice sites did not affect the reading frame of the transcript except for $\Delta 498-$ $1340 / \Delta 1655-1748$. In the transcript $\Delta 498-1340 / \Delta 1655-$ 1748 , a premature stop codon is generated at position c. 1805 .

\section{Confirmation of SILV splice variants in differentially pigmented skin}

In order to confirm alternative splice sites in the bovine SILV gene, we developed splice variant specific RT-PCR tests for an exemplary subset of the detected splice variants (Table 3, Figure 4). Splice variant profiling revealed the alternative splice variants $\Delta 498-1340, \Delta 816-1340$ and $\Delta 1185-1340$ in all differentially pigmented skins (Table 4). In contrast, we obtained a specific pattern for $\Delta 105-362$, which was not detected in non-pigmented, white skin of spotted individuals heterozygous for the 
Table 2: Regions of the bovine SILV mRNA tested for expression by RT-PCR in skin and non-pigmented body tissues

\begin{tabular}{|c|c|}
\hline Primer combination & Region \\
\hline
\end{tabular}

$\begin{array}{lll}\text { Eumelaneic skin } \quad \text { Phaeomelaneic skin } \quad \text { Non-pigmented tissues } & \end{array}$

$5 \mathrm{UTR}_{\mathrm{FI}}-\mathrm{EII}_{\mathrm{R} 2} \quad$ exon I - exon II $2039 \quad 2039, \mathrm{I} 102$ and multiple further fragments

1430 and further multiple bands

294

377

$856,700,331,175$

$687 ; 593$

479,324

456

404

274

n.a.

n.a.

n.a.

294

377

$856,700,331,175$

479,324

456

404

274

n.a. n.a.

\section{$856,700,331,175$}

(pg, tg, ki, ag, li, lu, he, br, ru, if, sf, sf, mg, fu, co, je, mu)

n.a.

n.a.

404 (pg, tg, ki, ag, li, lu, he, br, ru, if, sf, sf, mg, fu, co, je, mu)

n.a.

$E I_{F 3}-E 5_{R I} \quad$ exon $I-$ exon 5

pg: pituitary gland, tg: thyroid gland, ki: kidney, ag: adrenal gland, li: liver, lu: lung, he: heart, br: brain, ru: rumen, if: intestinal fat, sf: subcutaneous fat, pf: perirenal fat, mg: mammary gland, du: duodenum, co: colon, je: jejunum, mu: skeletal muscle. n.a.: not analyzed 


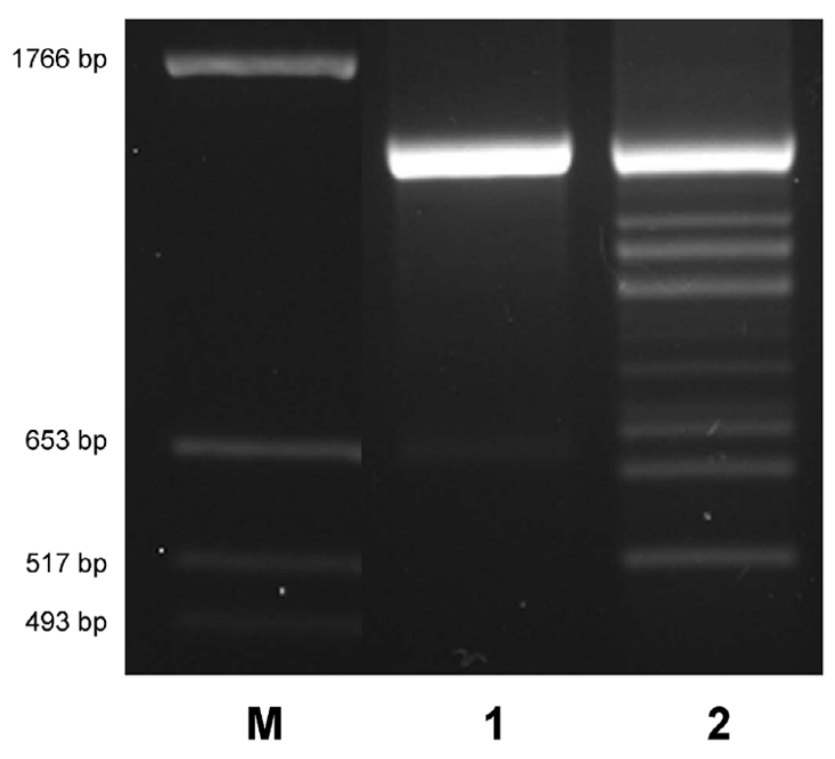

Figure 2

RT-PCR products in the SILV gene in eumelaneic black bovine skin. RT-PCR products were generated from pigmented, eumelaneic (black) bovine skin with primers spanning SILV exon I to exon $7\left(\mathrm{EI}_{\mathrm{F} 3} / \mathrm{E}_{\mathrm{RI}}\right)$. M: DNA marker, I: cloned constitutive SILV cDNA, 2: cDNA from eumelaneic (black), non-dilute $\left(D c^{d} / D c^{d}\right)$ skin

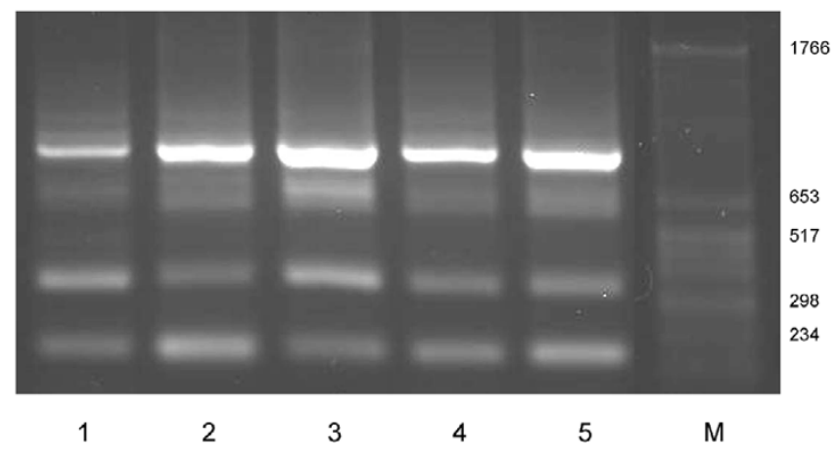

Figure 3

Expression of SILV in eumelaneic and phaeomelaneic bovine skin. RT-PCR products for the bovine SILV region spanning exon 5 to exon 7 were generated with primer $E 5_{\mathrm{FI}}$ $-E 7_{R I}$ in differentially pigmented bovine skin. I: non-pigmented skin from a heterozygous dilute $\left(D c^{D} / D c^{d}\right)$, eumelaneic $\left(E^{D} / E^{D}\right)$ spotted individual; 2: pigmented skin from a heterozygous dilute $\left(D c^{D} / D c^{d}\right)$, eumelaneic $\left(E^{D} / E^{D}\right)$ spotted individual; 3: crème white skin from a homozygous dilute $\left(D c^{D} / D c^{D}\right)$, eumelaneic $\left(E^{D} / E^{D}\right)$ non-spotted individual; 4: nonpigmented skin from a heterozygous dilute $\left(D c^{D} / D c^{d}\right)$, phaeomelaneic $\left(E^{\mathrm{e}} / E^{\mathrm{e}}\right)$ spotted individual; 5: pigmented skin from a homozygous non-dilute $\left(D c^{d} / D c^{d}\right)$, eumelaneic $(E D / E e)$ spotted individual; M: marker dilute locus $\left(D c^{D} / D c^{d}\right)$ regardless whether on a eumelaneic or a phaeomelaneic background. Notably, non-pigmented white skin of a spotted, homozygous non-dilute $\left(D c^{d} / D c^{d}\right)$ individual exhibited this splice site albeit at a lower level than the pigmented counterpart. Skin with a crème white coat color characteristic for individuals homozygous at the dilution locus $D c^{D} / D c^{D}$ also displayed the alternative splicing $\Delta 105-362$. It has to be noted that crème white skin has an essentially pigmented background with melanocytes [23], however, pigmentation is diluted to almost invisibility. In contrast, non-pigmented skin of spotted or piebald individuals is devoid of melanocytes resulting in a white coat color [10].

\section{Analysis of tissue specific SILV gene expression}

RT-PCR revealed a specific expression of the bovine SILV gene in all 17 investigated tissues from an adult individual: pituitary gland, thyroid gland, kidney, adrenal gland, liver, lung, heart, brain, rumen, intestinal fat, subcutaneous fat, perirenal fat, mammary gland, duodenum, colon, jejunum, skeletal muscle. All three SILV primer combinations tested spanning exon 1 to exon $5\left(\mathrm{E} 1_{\mathrm{F} 3}-\mathrm{E} 5_{\mathrm{R} 1}\right)$, exon 5 to exon $7\left(\mathrm{E} 5_{\mathrm{F} 1}-\mathrm{E} 7_{\mathrm{R} 1}\right)$ and exon 9 to exon $11\left(\mathrm{E} 9_{\mathrm{F} 1}-\right.$ $\mathrm{E} 11_{\mathrm{R} 2}$ ) confirmed this observation (Table 2). The relative amount as indicated by semi-quantitative RT-PCR differed between tissues: a strong SILV expression equivalent to skin was seen in a number of tissues with very divergent functions, e.g. thyroid gland and colon, whereas SILV was only weakly expressed in brain, muscle and fat tissues (Figure 5). Analysis with primers spanning exon 5 to exon $7\left(\mathrm{E} 5_{\mathrm{F} 1}-\mathrm{E} 7_{\mathrm{R} 1}\right)$ revealed at least two PCR fragments for all tissues with a pattern similar to that obtained for differentially pigmented skin tissues.

While alternative splice variants were rather uniformly distributed across the differentially pigmented skins, substantial variation was seen for the other tissues (Table 4). Only transcript variant $\Delta 105-362$ was tissue-specific for skin. Whereas splice variant $\Delta 816-1340$ could be detected in all seven tissues tested (Figure 6), $\Delta 1185-1340$ was only found in mammary gland at a low level.

\section{Discussion}

\section{Structure of the bovine SILV gene}

The bovine SILV gene shows a strong structural homology with the respective gene in human and mouse. The bovine mRNA (GenBank: EF065525) is separated into 11 exons and revealed a homology of $87 \%$ to the human (NM 006928.3) and $83 \%$ to mouse mRNA (NM 021882.4). At protein level, the similarities were 78 or $73 \%$, respectively. The sharp peak of transcription start sites detected in CAP finding RACE experiments and the putative TATA box of the SILV promoter located $30 \mathrm{bp}$ upstream correspond to the classical pattern of TATA box promoter architecture characteristic for genes highly con- 
Table 3: Splice site specific RT-PCR primer combinations applied for the detection of alternative bovine SILV transcripts

\begin{tabular}{|c|c|c|c|}
\hline Alternative splice site & Upstream primer & Downstream primer & $\begin{array}{l}\text { Expected alternative } \\
\text { transcript [bp] }\end{array}$ \\
\hline$\Delta 105-362$ & SPex $23_{\mathrm{FI}}$ TGTAGGGACCACAGAAGGGAG & E5 $_{\text {RI }}$ TAATGGTGAAGGCTGAACTGG & 311 \\
\hline$\Delta 498-1340$ & SPex56 ${ }_{F I}$ TGTCTGGAAGACCTGGGGCT & $\mathrm{E}_{\mathrm{R} 2}$ TGACACCCTGGCGATGAGATG & 264 \\
\hline$\Delta 660-1340$ & $\mathrm{E5}_{\mathrm{F} 2}$ GGGCACATATAACATGGAAGTG & SPex6 $_{R I}$ GCAGGGGACTCAGGGAGCCAG & 113 \\
\hline$\Delta 816-1340$ & SPex6A $A_{F I}$ CCTACACCTGGGACTTTGGCT & $\mathrm{E}_{\mathrm{R} 2}$ TGACACCCTGGCGATGAGATG & 265 \\
\hline$\Delta \mathrm{II} 85-1340$ & $\mathrm{SPex} \mathrm{B}_{\mathrm{FI}}$ CAACTGCAAAAGCTACAG $\overline{\mathbf{G C T}}$ & $\mathrm{E}_{\mathrm{R} 2}$ TGACACCCTGGCGATGAGATG & 265 \\
\hline$\Delta 1655-1748$ & $\mathrm{E7}_{\mathrm{F} 2}$ TGTGTTCTGTATCGCTATGGCTC & SPex ${ }_{R I}$ CTGAGGCCTGCTTCTTGCCCTG & 265 \\
\hline
\end{tabular}

Underlined, bold sequence: nucleotides specific for alternative splice site.

served in evolution [24]. Our RACE experiments in the eumelaneic (black) non-dilute $\left(D c^{d} / D c^{d}\right)$ skin yielded essentially an identical transcription start compared to a SILV mRNA obtained by 5'RACE from a homozygous dilute $\left(D c^{D} / D c^{D}\right)$, crème-white skin [18]. Thus, the use of alternative transcription starts can be formally excluded as the background for differences in coat color between dilute and non-dilute individuals.

\section{SILV transcription in phaeomelaneic and non-pigmented tissues}

Taking advantage of our animal model with individuals expressing exclusively eumelanin or phaeomelanin, our RT-PCR results prove that in cattle SILV expression in skin is not restricted to areas with eumelanocytes, because we also found SILV transcripts in phaeomelaneic and nonmelaneic skin. This result is in contrast to previous reports in mice [17] indicating that SILV expression could only be detected in cells synthesizing eumelanin. Whereas there are many studies about the melanophore-specific expression of SILV in the literature (reviewed by [4]), only one report in humans also describes SILV to be ubiquitously expressed [25]. This result is supported by 112 ESTs iso- lated from non-pigmented tissues in a total of 785 human SILV ESTs listed in the NCBI Unigene database [26]). Although no conclusion regarding SILV transcription can be drawn from bovine Unigene data base entries, our own experiments clearly reject the hypothesis that SILV expression is specific to eumelanocytes in cattle. Expression outside of pigmented tissues indicates that products of the bovine SILV gene seem to have a new, up to now unknown function additional to fibril formation in the course of melanosome development. Chakraborty et al. postulate a catalytic role of SILV in melanin synthesis [27]. But as melanin synthesis is restricted to melanophores in skin, uvea and other pigmented tissues [28], involvement of SILV in melanin synthesis would not explain SILV expression in tissues without melanophores. Consequently, the additional role of SILV expression postulated from our study has to exceed melanophore specific functions. Up to now, it is completely unclear, which role SILV transcription may play in e.g. thyroid gland or colon, two tissues with extremely different cell type composition, for which a high SILV expression was detected in our experiments. If indeed human SILV expression is also not restricted to melanophores as indicated by [25], cattle

Table 4: Expression of bovine SILV splice variants by splice site specific RT-PCR in differentially pigmented skin and non-pigmented tissues

\begin{tabular}{|c|c|c|c|c|c|c|}
\hline Tissues & $\Delta 105-362$ & $\Delta 498-1340$ & $\Delta 660-1340$ & $\Delta 816-1340$ & $\Delta 1185-1340$ & $\Delta 1655-1748$ \\
\hline Non-pigmented, heterozygous dilute, eumelaneic & - & + & + & + & ++ & + \\
\hline pigmented, heterozygous dilute, eumelaneic & ++ & ++ & + & ++ & ++ & ++ \\
\hline pigmented, homozygous dilute, eumelaneic & + & ++ & + & ++ & ++ & ++ \\
\hline Non-pigmented, heterozygous dilute, phaeomelaneic & - & + & + & + & ++ & + \\
\hline Pigmented, heterozygous dilute, phaeomelaneic & + & ++ & + & ++ & ++ & ++ \\
\hline Non-pigmented, homozygous non-dilute, eumelaneic & + & ++ & + & ++ & ++ & ++ \\
\hline Pigmented, homozygous non-dilute, eumelaneic & ++ & ++ & + & ++ & ++ & ++ \\
\hline liver & - & - & - & + & - & - \\
\hline duodenum & - & - & - & + & - & - \\
\hline pituitary gland & - & - & - & + & - & - \\
\hline lung & - & + & + & + & - & - \\
\hline heart & - & - & - & + & - & - \\
\hline kidney & - & + & - & + & - & + \\
\hline mammary gland & - & + & - & + & + & + \\
\hline
\end{tabular}

-: no expression detected, + expression detected, ++ enhanced expression detected 


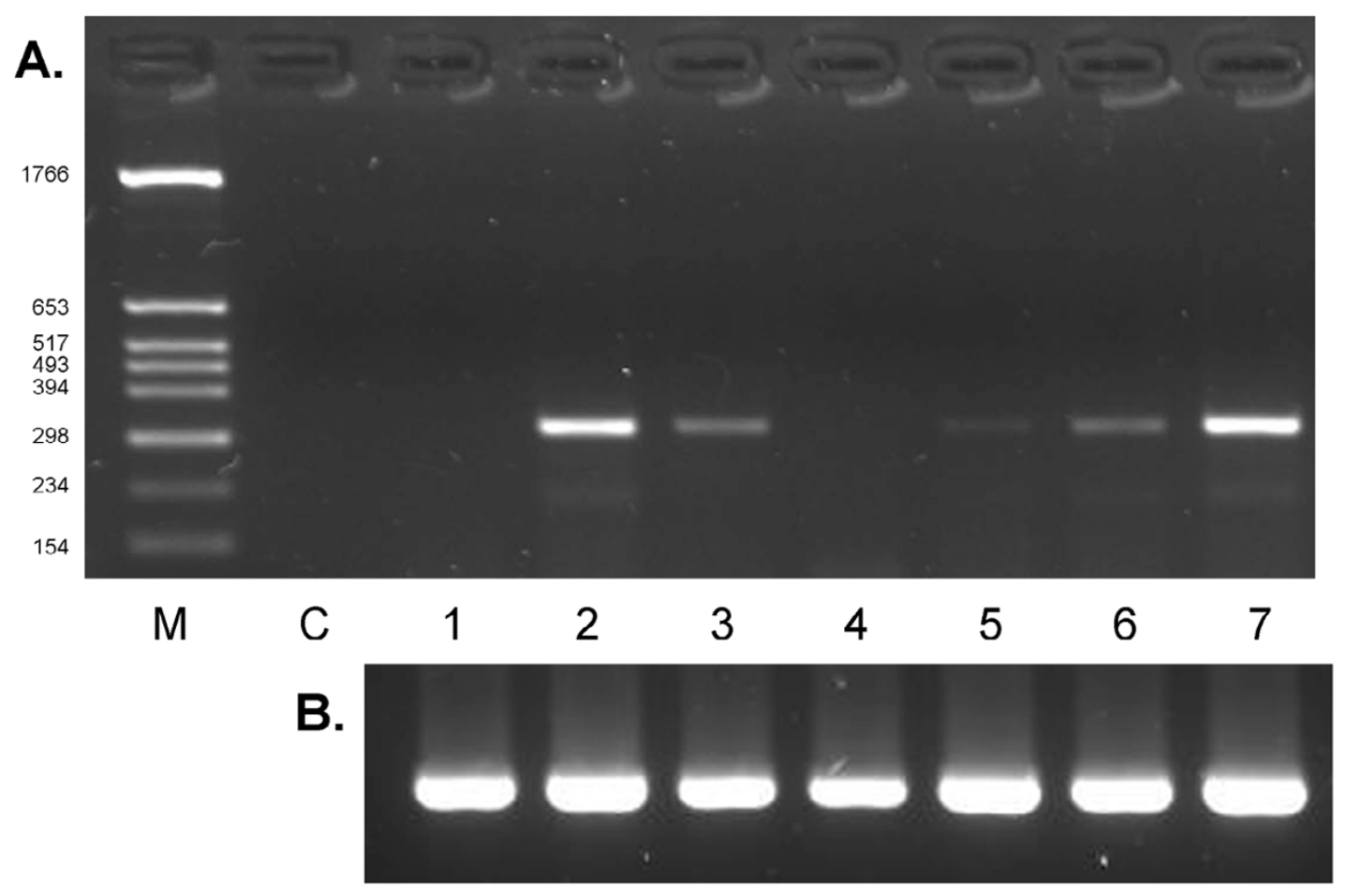

\section{Figure 4}

Splice site specific SILV RT-PCR in differentially pigmented bovine skin. A. Detection of bovine SILV splice variant $\triangle 105-362$ in differentially pigmented skin. RT-PCR products generated by splice site specific RT-PCR with primers SPex23 ${ }_{F I}-$ $E 5_{R I}$. M: marker; C: negative control, I: non-pigmented skin from a heterozygous dilute $\left(D c^{D} / D c^{d}\right)$, eumelaneic $\left(E^{D} / E^{D}\right)$ spotted individual; 2: pigmented skin from a heterozygous dilute $\left(D c^{D} / D c^{d}\right)$, eumelaneic $\left(E^{D} / E^{D}\right)$ spotted individual; 3: crème white skin from a homozygous dilute $\left(D c^{D} / D c^{D}\right)$, eumelaneic $\left(E^{D} / E^{D}\right)$ non-spotted individual ; 4: non-pigmented skin from a heterozygous dilute $\left(D c^{D} / D c^{d}\right)$, phaeomelaneic $(E \mathrm{e} / E \mathrm{e})$ spotted individual; 5: pigmented skin from a heterozygous dilute $\left(D c^{D} / D c^{d}\right)$, phaeomelaneic $\left(E^{e} / E^{e}\right)$ spotted individual; 6: non-pigmented skin from a homozygous non-dilute $\left(D c^{d} / D c^{d}\right)$, eumelaneic $\left(E^{D} / E^{e}\right)$ spotted individual; 7: pigmented skin from a homozygous non-dilute $\left(D c^{d} / D c^{d}\right)$, eumelaneic $\left(E^{D} / E^{e}\right)$ spotted individual. B. RT-PCR products generated with GAPDH primers.

may serve as an appropriate model to investigate its potential function in non-melanophores.

\section{Alternative splicing in SILV affecting functionally relevant domains}

RT-PCR with an overlapping panel of primer pairs indicated nine alterative splice sites in the bovine SILV gene resulting in splicing of cryptic introns predominantly affecting exon 6, but also exons 2, 3, 4, 5 and exon 9. Thus, the splicing pattern comprises the use of single or combined cassette exons and alternative 5' splice sites resulting predominantly in deletions of single or multiple exons, which is in line with other comprehensive studies investigating alternative splicing [21]. Sequence alignment of the bovine SILV cDNA with the nine cattle ESTs homologous to SILV, which are deposited in the Unigene database [26], did not indicate alternative splicing. However, the confirmed alternative SILV transcripts in cattle from our study are in line with previous experiments in humans describing two alternative splice sites in exon 6 and exon 9 of the SILV gene [19]. The extent of alternative splicing seen in cattle exceeds the number of published alternative transcripts in humans substantially, and we even cannot exclude that further splice variation is present in cattle. The Alternative Splicing Database [29,30] collecting electronic data on constitutive and alternative transcripts lists entries exclusively for human SILV and indicates that the number of alternative transcripts in humans is also presumably higher than presently considered. Interestingly, humans and cattle are the only species for which alternative transcripts have been experimentally established $[19,29]$. No additional transcripts are published e.g. in mice.

Comparative analysis of the bovine SILV protein with the respective counterpart in human according [4] suggested that several functional domains of the SILV protein as defined by [31] should be affected by alternative splicing 

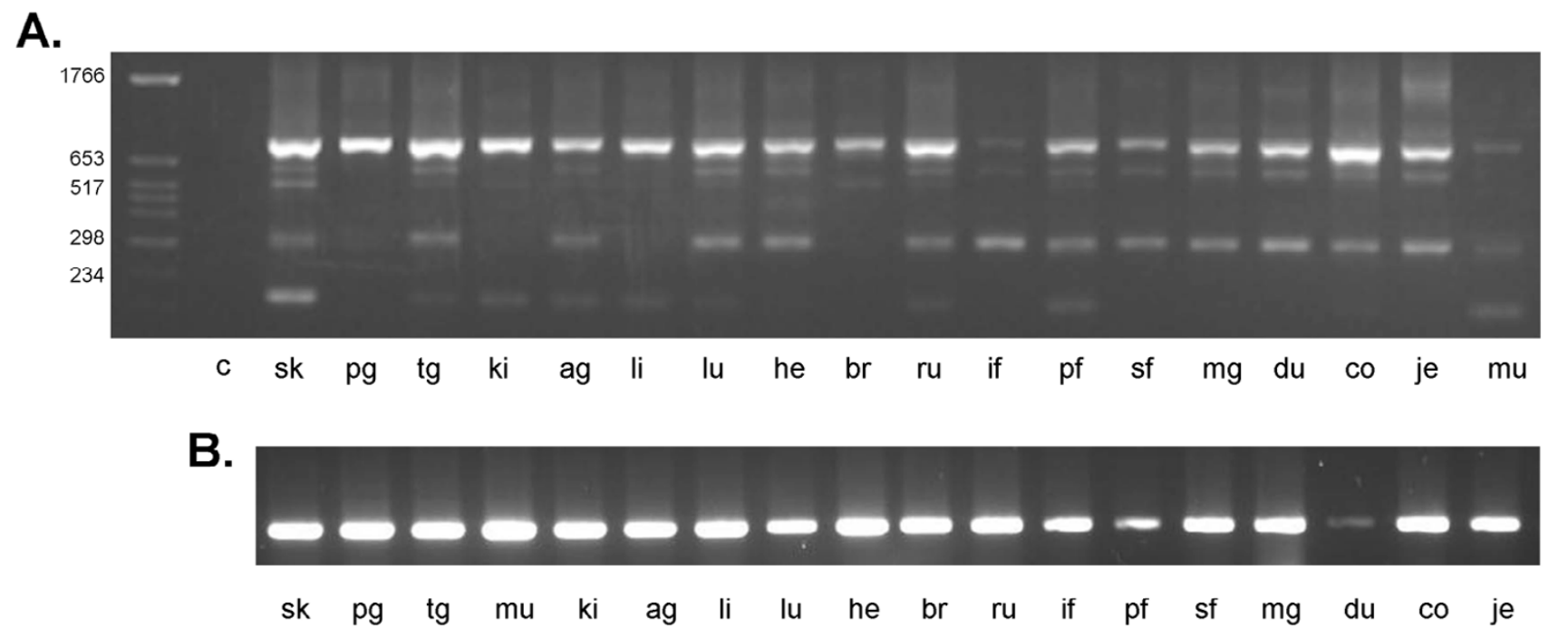

\section{Figure 5}

Expression of SILV in a collection of non-pigmented bovine tissues. A: SILV RT-PCR products generated with primers spanning exon 5 to exon $7\left(E 5_{\mathrm{FI}}-E 7_{\mathrm{RI}}\right)$ in RNA from non-pigmented tissues; sk: skin, pg: pituitary gland, tg: thyroid gland, ki: kidney, ag: adrenal gland, li: liver, lu: lung, he: heart, br: brain, ru: rumen, if: intestinal fat, pf: perirenal fat, sf: subcutaneous fat, mg: mammary gland, du: duodenum, co: colon, je: jejunum, mu: skeletal muscle. B. RT-PCR products generated with GAPDH primers in different non-pigmented tissues.

in cattle. Splice variant $\Delta 105-362$ characterized by the complete skipping of exons 2 and 3 results in loss of the proximal part of the $\mathrm{N}$ terminal domain (NTD) of the bovine SILV protein. Thus, skipping of exons 2 and 3 would affect the posttranslational modification of the protein substantially, because the NTD carries the majority of SILVs' glycosylation sites as reviewed by [4]. The alternative transcripts $\Delta 363-1340, \Delta 498-1340$ and
$\Delta 660-1340$ lack 326,281 or 227 amino acids of the constitutive transcript, respectively, representing the $\mathrm{C}$ terminal part of the $\mathrm{N}$ terminal domain and the entire Polycystic kidney disease (PKD) and Repeat (RPT) domains. While the PKD has an immunoglobulin folding structure and is thought to mediate protein-protein interactions, the RPT domains seems to be necessary for fibril formation in melanosomes [31]. The entire RPT domain

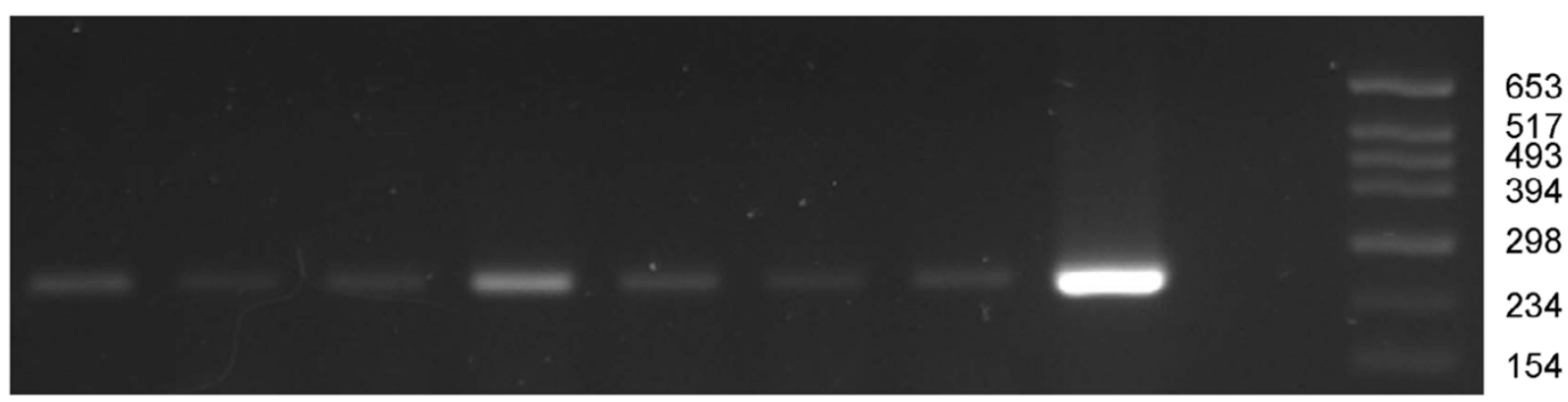

mg ki he lu pg du li $\quad$ sk $\quad$ c $\quad M$

\section{Figure 6}

Splice site specific SILV RT-PCR in non-pigmented bovine tissues. Detection of SILV splice variant $\Delta 816-1340$ by splice site specific RT-PCR with primers SPex6A $\mathrm{FI}_{1}-\mathrm{E} \mathrm{g}_{\mathrm{R} 2}$ in RNA from non-pigmented tissues. mg: mammary gland, ki: kidney, he: heart, lu: lung, pg: pituitary gland, du: duodenum, li: liver, sk: skin. M: marker; C: negative control 
is also missing in the $\Delta 816-1340$ transcript in addition to the distal PKD domain. Transcript $\Delta 1185-1340$ lacks the distal part of the RPT domain, whereas $\Delta 1332-1340$ is devoid of 3 amino acids of the Gap2 domain. Splice variant $\Delta 1655-1748$ is the only transcript with a disrupted reading frame and a premature stop codon generating a truncated protein without transmembrane and $\mathrm{C}$ terminal domain or possibly inducing a nonsense-mediated mRNA decay [32]. While the Kringle-like domain and the transmembrane domain seem to be rather invariable, the RPT domain is most frequently affected by the different splice variants in our data set. Experiments with human SILV deletion constructs showed that a protein lacking the Repeat domain ( $\triangle$ RPT SILV) showed an appropriate intracellular trafficking [31]. However, HELA cells overexpressing $\triangle$ RPT SILV formed only abnormal fibrils, indicating that the RPT domain plays a crucial role in the development of the striated fibrillar structure in melanosomes. Hoashi et al. [31] used HMB45, an antibody frequently employed for melanoma diagnostic as a probe specific for melanosomal fibrils and showed that its epitope is located in the second and third amino acid repeat of the RPT domain. Thus, bovine transcripts lacking the respective part of the RPT domain (like 498-1340, $\Delta 660-1340$ and $\Delta 816-1340$ in our study) should not be able to form intact fibrils, a process central to appropriate melanosome development as determined for human SILV. Interestingly, the two of the four isoforms of SILV in humans due to alternative splicing also affect the RPT domain albeit not the epitope for HMB45 [31]. The alternative splice variants lacking entire functional domains as confirmed for the bovine SILV gene represent ideal candidates for further study into the potential effects of alternative splicing on function [21].

\section{Variation in alternative splicing of SILV with respect to coat color phenotype}

In cattle, we did not find any mutation in the coding SILV sequence that could convincingly be associated with phaeomelanin coat color dilution in a $\mathrm{F}_{2}$ resource population based on the Charolais and the Holstein breed [14]. In dogs, Clark et al., [12] described a mutation in intron 10 of the canine SILV gene that was associated with coat color dilution and concluded that the mutation might impair correct splicing of the canine SILV transcript. Thus, another as yet undetected mutation in the genomic sequence of the bovine SILV gene could possibly affect the structure of the SILV mRNA, representing the genetic background for phaeomelanin dilution in cattle. Because we could confirm SILV expression in eumelaneic and also phaeomelaneic skin, any genetic variant affecting regulation or coding structure of the gene might theoretically also affect phaeomelanin dilution in cattle, although presently there is no indication, which function SILV may exert on maturation of phaeomelanosomes. Thus, given our expression data the SILV gene could not formally be rejected as the background for phaeomelanin dilution in cattle. However, neither the transcription start, which was conserved between homozygous dilute $\left(D c^{D} / D c^{D}\right)$ and non-dilute $\left(D c^{d} / D c^{d}\right)$ individuals, nor the distribution of splice variants in the differentially pigmented skins, convincingly explained the differences in dilution phenotype. Hence, there is no indication that variation in the primary sequence of the SILV protein either due to variation in the coding sequence or due to alternative splicing is responsible for dilution of phaeomelanin in cattle.

Whereas the pattern of transcript variants is rather similar across the panel of differentially pigmented skin, the variability of splice variants detected in other tissues points towards a tissue specific splicing mechanism. This may represent a tool for adapting SILV expression to the requirements of the respective cells [20].

\section{Conclusion}

Although the structure of the SILV gene is conserved across a variety of species including cattle, its pattern of transcription shows substantial differences regarding alternative splicing between cattle and human on the one side and mice on the other. Our experiments provide evidence for a ubiquitous transcription of the bovine SILV gene not restricted to pigmented cells and show a striking variety of alternative splice sites. These results indicate that potentially SILV may have functions exceeding melanosome development. This would have to be considered in future investigations concerning melanoma diagnostic and therapy and also in studies taking SILV as a model for amyloid formation [33] or for intracellular transport mechanisms. The similarity in expression pattern compared to human and the variety of alternative transcripts predestine bovine SILV as an adequate animal model.

Whereas alternative splicing is a well established regulatory mechanism for gene expression [20], the confirmed alternative SILV transcripts are in line with the hypothesis of the new postulated additional SILV functions exceeding synthesis and deposition of melanin. This hypothesis is supported by the detection of SILV transcripts in nonmelanophores in our study. However, it has to be considered that our analyses are restricted to the transcription level. Thus, subsequent steps modulating SILV expression due to e.g. nonsense mediated decay [32] and translational and posttranslational modification require further investigation to confirm the postulated additional functions of the SILV gene. Due to its extensive, up to now unique pattern of alternative splicing, bovine splice variants represent a naturally occurring model for the function of the domains located in the spliced regions of the SILV and for the alternative functions postulated for SILV. 
Furthermore, factors regulating the processes of alternative splicing in the different tissues can be investigated exemplarily.

\section{Methods}

\section{Tissue samples}

For our study, we included individuals from a Charolais $x$ German Holstein $\mathrm{F}_{2}$ cattle resource population [34]. The resource population segregates for the coat color trait loci (i) Dilution $(D c)$ responsible for coat color dilution, (ii) Extension (E) responsible for an eumelaneic (black) or a phaeomelaneic (red) phenotype, and (iii) Spotted (S) resulting in a pigmented-white spotting pattern similar to piebald in mice. We collected differentially pigmented neck skin after slaughter: (1) black and white sections of a homozygous non-dilute $\left(D c^{d} / D c^{d}\right)$, spotted $(s / s)$ eumelaneic $\left(E^{D} / E^{e}\right)$ animal, (2) diluted colored and white sections of an eumelaneic $\left(E^{D} / E^{D}\right)$, heterozygous $D c^{D} / D c^{d}$, spotted $(s / s)$ individual, (3) diluted colored and white sections of a phaeomelaneic $\left(E^{e} / E^{e}\right)$, heterozygous $D c^{D} / D c^{d}$, spotted $(s / s)$ individual and $(4)$ the crème white skin of a homozygous non-dilute $\left(D c^{D} / D c^{D}\right)$, non-spotted, eumelaneic $\left(E^{D} / E^{D}\right)$ individual. Hair and subcutaneous tissue was removed and the remaining cutis was snap frozen. Genotypes of the individuals for the SILV c64G>A mutation, presumably responsible for dilution of eumelanin, were determined as described by [14]. Genotypes at the dominant-recessive Extension locus were determined by sequencing of the MC1R gene. Primers $M_{C} 1 R_{F 1}$ (5'-TACTACTTTATCTGCTGCCTG-3') and $\mathrm{MC1R}_{\mathrm{R} 1}$ (5'-GCGTAGAAGATGGAGATGTAG-3') flanking the causal mutations for the alleles $E^{D}$ (dominant black, eumelanin) and $E^{e}$ (recessive red, phaeomelanin) were used for amplification in genomic DNA of individuals tested and consecutive sequencing of the resulting PCR products. In addition to the differentially pigmented skin samples, 17 tissues (pituitary gland, thyroid gland, kidney, adrenal gland, liver, lung, heart, brain, rumen, intestinal fat, subcutaneous fat, perirenal fat, mammary gland, duodenum, colon, jejunum, skeletal muscle) from an adult female Charolais $\times$ German Holstein $\mathrm{F}_{2}$ individual were collected at slaughter and immediately snap frozen. Total RNA was isolated with the NucleoSpin ${ }^{\circledast}$ RNAII kit (Macherey and Nagel) except all fat tissues, which were isolated with the RNeasy Lipid tissues kit (Qiagen), essentially as described by the manufacturers.

\section{Analysis of skin SILV gene expression}

The isolated RNA was reverse transcribed into cDNA according to [35] with a primer mix containing Oligo $\mathrm{dT}_{(12-18)}$ and a gene specific primer from the 3'UTR of the SILV mRNA (E11 $1_{\mathrm{R} 2}$, Table 1). The resulting CDNAs were amplified with GO-Taq polymerase (Promega) under standard conditions and primers as indicated in Table 1 and Table 2. Due to confirmed splice variants in the RPT and in the GAP3 domain of the human SILV gene and because we obtained suggestive additional bovine SILV transcripts in initial investigations, the entire bovine SILV cDNA was examined for additional splice sites using overlapping PCR primer combinations (Table 2). These investigations were carried out in skin of different coat color phenotypes. The generated PCR fragments were separated on agarose gels. As a control, expression of glyceraldehyde-3-phosphate dehydrogenase (GAPDH) was determined by RT-PCR as described [35].

\section{Sequencing of SILV transcripts}

The analysis of SILV transcripts in differently pigmented skin and non-pigmented body tissues detected more than one RT-PCR fragment for several primer combinations. The respective fragments were excised from the agarose gel, purified using the Nucleospin Extract II kit (Macherey and Nagel) and sequenced on a capillary sequencer (ABI 310, Applied Biosystems; MEGABACE, GE Healthcare) using BigDye ${ }^{\circledast}$ (Applied Biosystems) chemistry. Two prominent RT-PCR fragments $>1000$ bp generated with primers spanning exon 1 to exon $11\left(5 \mathrm{UTR}_{\mathrm{F} 1}-\mathrm{E} 11_{\mathrm{R} 2}\right.$, Table 1) were excised from the gel, purified, and cloned into the pCR4 Blunt TOPO vector (Invitrogen) according the manufacturers instructions. Seven size fractionated subsets of RT-PCR fragments generated by primers enclosing exon 1 to exon $7\left(E 1_{\mathrm{F} 3}-\mathrm{E} 7_{\mathrm{R} 1}\right.$, Table 1$)$ were excised from the agarose gel, purified and cloned into pDrive vector (Qiagen) according to the manufacturers instructions. Clones with different insert sizes according to colony PCR were sequenced on a capillary sequencer (ABI 310, Applied Biosystems; MEGABACE, GE Healthcare) using BigDye $^{\circledast}$ (Applied Biosystems) chemistry.

\section{SILV RNA 5' RACE experiments}

To determine the transcription start site for the bovine SILV gene and to test for alternative promoters, 5' RACE experiments with the GeneRacer Kit (Invitrogen) based on RNA ligase mediated and oligo-capping methods were performed. After CAP selection in a preparation of total RNA from black skin of a eumelaneic $\left(E^{D} / E^{D}\right)$, non-dilute $\left(D c^{d} / D c^{d}\right)$ individual, reverse transcription with oligo dT and re-amplification with the RACE $5^{\prime}$ oligo and a SILV specific primer from exon 7 (RACE_E7N, Table 1) was carried out according to the manufacturers instructions. The generated fragments were cloned into pDrive vector using the Qiagen PCR cloning kit (Qiagen). Clones with different insert sizes according to colony PCR were sequenced. Sequences obtained were aligned to the deposited SILV mRNA (GenBank: EF065525).

\section{Confirmation of SILV splice variants}

To confirm the detected SILV splice variants, SILV cDNA samples were investigated by splice site specific RT-PCR. For this purpose, SILV cDNAs were generated by reverse 
transcription with the $\mathrm{E} 11_{\mathrm{R} 2}$ primer from total RNA of skins differing in coat color phenotype. Afterwards, the cDNAs were subjected to PCR amplification with one SILV primer corresponding to the sequence of the constitutive SILV mRNA and another primer specific for each splice variant, respectively (Table 1 , Table 3 ). Splice variant specific primers were designed to bridge the splice ends of the addressed alternative splice site. For negative control, DNA of a plasmid with a constitutive SILV cDNA insert was included.

\section{SILV expression in non-pigmented tissues}

Finally, SILV expression was screened in a collection of 17 total RNAs from non-pigmented tissues (pituitary gland, thyroid gland, kidney, adrenal gland, liver, lung, heart, brain, rumen, intestinal fat, subcutaneous fat, perirenal fat, mammary gland, duodenum, colon, jejunum, skeletal muscle). Analogous to the RT-PCR in skin tissue, the different RNAs were reversely transcribed and amplified by using primers corresponding to the constitutive SILV cDNA sequence in combinations covering exon 1 to exon $5\left(\mathrm{E} 1_{\mathrm{F} 3} / \mathrm{E} 5_{\mathrm{R} 1}\right)$, exon 5 to exon $7\left(\mathrm{E} 5_{\mathrm{F} 1} / \mathrm{E} 7_{\mathrm{R} 1}\right)$ and exon 9 to exon $11\left(\mathrm{E} 9_{\mathrm{F} 1} / \mathrm{E} 11_{\mathrm{R} 2}\right.$, Table 2$)$.

Because there was evidence on alternative splicing in nonpigmented skin, a collection of eight non-pigmented other tissues (liver, duodenum, pituitary gland, lung, heart, kidney, mammary gland) was further investigated for alterative splicing by splice variant specific RT-PCR analogous to the procedure described for skin. The respective primer combinations are listed in Table 3.

\section{Competing interests}

The author(s) declares that there are no competing interests.

\section{Authors' contributions}

CK conceived, designed and coordinated the study, carried out PCR analysis of RNAs, participated in sequence alignments and drafted the manuscript. RW participated in coordination of the study, participated in sequence alignments, carried out the RACE and splice variant specific experiments, and helped drafting the manuscript. All authors read and approved the final manuscript.

\section{Acknowledgements}

We thank Astrid Kühl, Simone Wöhl, Marlies Deutscher and Oda Haufft for skilful technical assistance. The continuous support of our colleagues at the FBN Dummerstorf involved in generation and care of the SEGFAM $F_{2}$ resource population is thankfully acknowledged.

\section{References}

I. Spanknebel K, Coit DG, Bieligk SC, Gonen M, Rosai J, Klimstra DS: Characterization of micrometastatic disease in melanoma sentinel lymph nodes by enhanced pathology - Recommendations for standardizing pathologic analysis. Am J Surg Pathol 2005, 29:305-317.
2. Tsukamoto K, Ueda M, Hirata S, Osada A, Kitamura R, Takahashi T, Ichihashi M, Shimada S: gpI00 mRNA is more sensitive than tyrosinase mRNA for RT-PCR amplification to detect circulating melanoma cells in peripheral blood of melanoma patients. J Dermatol Sci 2000, 23:126-I3I.

3. Bakker ABH, Schreurs MWJ, Deboer AJ, Kawakami Y, Rosenberg SA, Adema GJ, Figdor CG: Melanocyte Lineage-Specific Antigen Gp 100 Is Recognized by Melanoma-Derived Tumor-Infiltrating Lymphocytes. J Exp Med 1994, I79:1005-1009.

4. Theos AC, Truschel ST, Raposo G, Marks MS: The Silver locus product Pmel I 7/gp I00/Silv/ME20: controversial in name and in function. Pigment Cell Res 2005, 1 8:322-336.

5. Berson JF, Harper DC, Tenza D, Raposo G, Marks MS: Pmell 7 initiates premelanosome morphogenesis within multivesicular bodies. Mol Biol Cell 200I, I 2:345I-3464.

6. Brooks SA, Terry RB, Bailey E: A PCR-RFLP for KIT associated with tobiano spotting pattern in horses. Anim Genet 2002, 33:30I-303.

7. Rees JL: Genetics of hair and skin color. Ann Rev Genet 2003, 37:67-90.

8. Du JY, Fisher DE: Identification of aim-I as the underwhite mouse mutant and its transcriptional regulation by MITF. J Biol Chem 2002, 277:402-406.

9. Olson TA: Genetics of colour variation. In The Genetics of Cattle Edited by: Fries R and Ruvinsky A. Wallingford, UK, CABI; 1999:33-54.

10. Schaible RH: Clonal Distribution of Melanocytes in PiebaldSpotted and Variegated Mice. J Exp Zool 1969, 172:18I-199.

II. Brunberg E, Andersson L, Cothran G, Sandberg K, Mikko S, Lindgren $\mathrm{G}$ : A missense mutation in PMELI 7 is associated with the Silver coat color in the horse. BMC Genetics 2006, 7:46.

12. Clark LA, Wahl JM, Rees CA, Murphy KE: Retrotransposon insertion in SILV is responsible for merle patterning of the domestic dog. Proc Natl Acad Sci U S A 2006, 103(5): | 376-| 38 |.

13. Kerje S, Sharma P, Gunnarsson U, Kim H, Bagchi S, Fredriksson R, Schutz K, Jensen P, von Heijne G, Okimoto R, Andersson L: The Dominant white, Dun and Smoky color variants in chicken are associated with insertion/deletion polymorphisms in the PMELI 7 gene. Genetics 2004, 168:1507-1518.

14. Kühn C, Weikard R: An investigation into the genetic background of coat colour dilution in a Charolais - German Holstein F2 resource population. Anim Genet 2007, 38:109-II3.

15. Martinez-Esparza MM, Jimenez-Cervantes C, Bennett DC, Lozano JA, Solano F, Garcia-Borron JC: The mouse silver locus encodes a single transcript truncated by the silver mutation. Mamm Genome 1999, 10: | 168-1 171.

16. Reissmann M, Bierwolf J, Brockmann GA: Two SNPs in the SILV gene are associated with silver coat colour in ponies. Anim Genet 2007, 38: I-6.

17. Kobayashi T, Vieira WD, Potterf B, Sakai C, Imokawa G, Hearing V]: Modulation of melanogenic protein expression during the switch from eumelanogenesis to pheomelanogenesis. J Cell Sci 1995, 108:2301-2309.

18. Oulmouden A, Julien R, Laforet JM, Leveziel $\mathrm{H}$ : Use of silver gene for authentication of the racial origin of animal populations, and of the derivative products thereof. WO2005/019473. 2005.

19. Nichols SE, Harper DC, Berson JF, Marks MS: A novel splice variant of Pmell7 expressed by human melanocytes and melanoma cells lacking some of the internal repeats. J Invest Dermatol 2003, 1 21:821-830.

20. Stamm S, Ben-Ari S, Rafalska I, Tang YS, Zhang ZY, Toiber D, Thanaraj TA, Soreq H: Function of alternative splicing. Gene 2005, 344:I-20.

21. Tress ML, Martelli PL, Frankish A, Reeves GA, Wesseling JJ, Yeats C, Olason PI, Albrecht M, Hegyi H, Raimondo AGD, Lagarde J, Laskowski RA, Lopez G, Sadowski MI, Watson JD, Fariselli P, Rossi I, Nagy A, Kai W, Storling Z, Orsini M, Assenov Y, Blankenburg H, Huthmacher C, Ramirez F, Schlicker A, Denoeud F, Jones P, Kerrien F, Orchard S, Antonarakis FE, Reymond A, Birney E, Brunak S, Casadio R, Guigo R, Harrow J, Hermjakob H, Jones DT, Lengauer T, Orengo CA, Patthy L, Thornton JL, Tramontano A, Valencia A: The implications of alternative splicing in the ENCODE protein complement. Proc Natl Acad Sci U S A 2007, 104(1 3):5495-5500.

22. NCBI map viewer 2007 [http://www.ncbi.nlm.nih.gov/mapview/]. 
23. Guibert S, Girardot M, Leveziel H, Julien R, Oulmouden A: Pheomelanin coat colour dilution in french cattle breeds is not correlated with the TYR, TYRP I and DCT transcription levels. Pigment Cell Res 2004, 1 7:337-345.

24. Carninci P, Sandelin A, Lenhard B, Katayama S, Shimokawa K, Ponjavic J, Semple CAM, Taylor MS, Engstrom PG, Frith MC, Forrest ARR, Alkema WB, Tan SL, Plessy C, Kodzius R, Ravasi T, Kasukawa T, Fukuda S, Kanamori-Katayama M, Kitazume Y, Kawaji H, Kai C, Nakamura M, Konno H, Nakano K, Mottagui-Tabar S, Arner P, Chesi A, Gustincich S, Persichetti F, Suzuki H, Grimmond SM, Wells CA, Orlando V, Wahlestedt C, Liu ET, Harbers M, Kawai J, Bajic VB, Hume DA, Hayashizaki Y: Genome-wide analysis of mammalian promoter architecture and evolution. Nature Genet 2006, 38:626-635.

25. Brouwenstijn N, Slager EH, Bakker ABH, Schreurs MW], Van der Spek CW, Adema GJ, Schrier PI, Figdor CG: Transcription of the gene encoding melanoma-associated antigen gpl00 in tissues and cell lines other than those of the melanocytic lineage. BrJ Cancer 1997, 76:1562-1566.

26. NCBI Unigene database 2007 [http://www.ncbi.nlm.nih.gov/ent rez/query.fcgi? db=unigene].

27. Chakraborty AK, Platt JT, Kim KK, Kwon BS, Bennet DC, Pawelek JM: Polymerization of 5,6-dihydroxyindole-2-carboxylic acid to melanin by the pmel 17 silver locus protein. Eur J Biochem 1996, 236: $180-188$.

28. Hearing VJ, Tsukamoto K: Enzymatic Control of Pigmentation in Mammals. FASEB Journal I991, 5:2902-2909.

29. The Alternative Splicing Database 2007 [http://www.ebi.ac.uk/ asd/index.html].

30. Thanaraj TA, Stamm S, Clark F, Riethoven JJ, Le Texier V, Muilu J: ASD: the Alternative Splicing Database. Nucl Acids Res 2004, 32:D64-D69.

31. Hoashi T, Muller J, Vieira WD, Rouzaud F, Kikuchi K, Tamaki K, Hearing $\mathrm{VJ}$ : The repeat domain of the melanosomal matrix protein PMELI7/GPI 00 is required for the formation of organellar fibers. J Biol Chem 2006, 28I:2 I I 98-2। 208.

32. Maquat LE: Nonsense-mediated mRNA decay: Splicing, translation and mRNP dynamics. Nat Rev Mol Cell Biol 2004, 5(2):89-99.

33. Fowler DM, Koulov AV, Alory-Jost C, Marks MS, Balch WE, Kelly JW: Functional amyloid formation within mammalian tissue. PLoS Biol 2006, 4(I): 100-107.

34. Kühn C, Bellmann O, Voigt J, Wegner J, Guiard V, Ender K: An experimental approach for studying the genetic and physiological background of nutrient transformation in cattle with respect to nutrient secretion and accretion type. Arch Anim Breed 2002, 45:317-330.

35. Weikard R, Kuhn C, Goldammer T, Freyer G, Schwerin M: The bovine PPARGCIA gene: molecular characterization and association of an SNP with variation of milk fat synthesis. Physiol Genomics 2005, 2 I: I-13.

\section{Publish with Bio Med Central and every scientist can read your work free of charge}

"BioMed Central will be the most significant development for disseminating the results of biomedical research in our lifetime. "

Sir Paul Nurse, Cancer Research UK

Your research papers will be:

- available free of charge to the entire biomedical community

- peer reviewed and published immediately upon acceptance

- cited in PubMed and archived on PubMed Central

- yours - you keep the copyright

Submit your manuscript here:

http://www.biomedcentral.com/info/publishing_adv.asp
BiolMedcentral 